\title{
Long-Standing Asymptomatic Inguinoscrotal Hernia
}

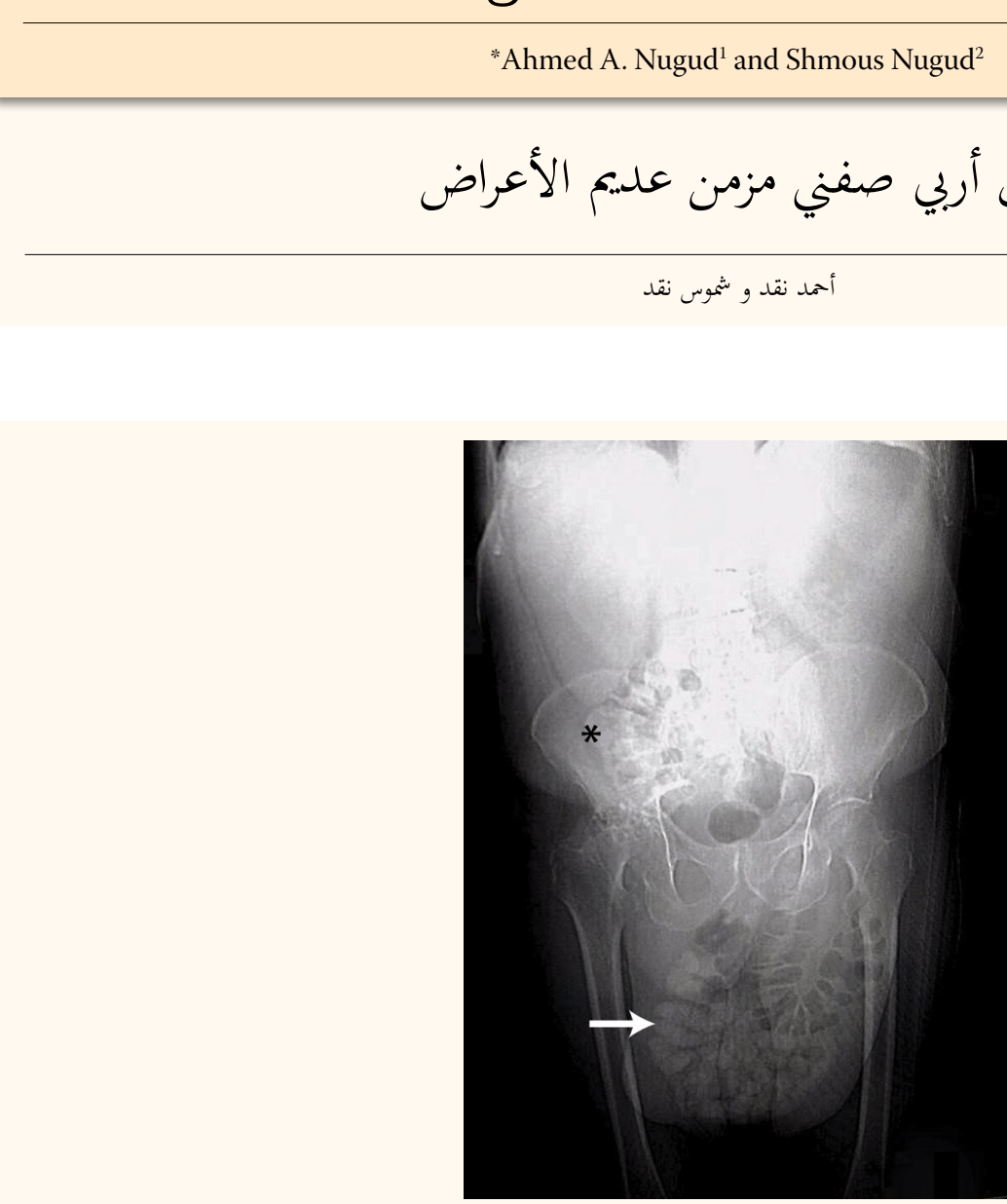

Figure 1: Pelvic X-ray of a 67-year-old man with a long-standing asymptomatic inguinoscrotal mass showing extensive inguinal herniation (arrow) in addition to degenerative changes in the right hip joint (asterisk).

A 67-YEAR-OLD MAN PRESENTED TO THE emergency department of Kuwait Hospital, Sharjah, United Arab Emirates, in 2016 after multiple episodes of biliary vomiting with abdominal pain over the preceding 24 hours. He had had no bowel motion during the previous 10 days. On examination, he was found to have a long-standing asymptomatic inguinoscrotal mass which had first been noticed 30 years before; since then, it had been increasing in size and had recently become irreducible. He was retired and had a history of atrial fibrillation, hypertension, scoliosis, gout and peptic ulcer disease. In addition, he had smoked one pack of cigarettes daily for 25 years and sometimes drank alcohol socially. An abdominal $\mathrm{X}$-ray revealed degenerative changes in his right hip [Figure 1]. Computed tomography showed a hugely dilated stomach with the distal part of the stomach herniating through the left inguinal canal to the scrotum, along with loops of the small bowel and sigmoid colon [Figures 2 and 3]. The patient refused surgery and was subsequently lost to follow-up.

\section{Comment}

Hernias are usually treated with surgical repair in order to prevent possible complications (i.e. hernia incarceration or strangulation) which can lead to bowel obstruction and, eventually, to intestinal ischaemia. ${ }^{1}$ The estimated annual risk of a hernia is approximately three per thousand patients. ${ }^{1}$ Direct inguinal hernias usually occur only among older men, as ageing and stress/strain weaken the abdominal muscles around the inguinal canal; in comparison, women rarely suffer from this type of hernia. ${ }^{2} \mathrm{~A}$ recent study by Isik et al. 


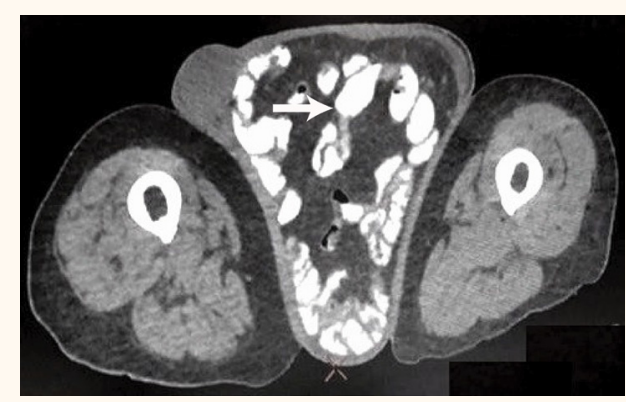

Figure 2: Horizontal computed tomography of a 67-year-old man with a long-standing asymptomatic inguinoscrotal mass showing large bowel loops passing into the scrotum (arrow).

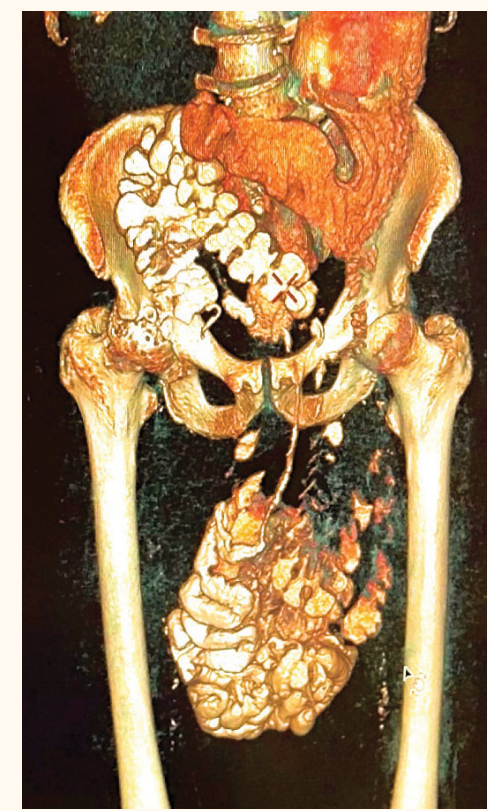

Figure 3: Three-dimensional reconstructed computed tomography of a 67-year-old man with a long-standing asymptomatic inguinoscrotal mass showing a hugely dilated fluid-filled stomach with the distal part of the stomach herniating through the left inguinal canal into the left scrotum. In addition, the stomach displaced the small bowel loops on the right side which, along with most of the sigmoid, descending and transverse colon, passed through the left inguinal canal. has suggested that inguinal hernias develop as a result of changes at the tissue level involving matrix metalloproteinases. ${ }^{3}$ The current case describes a patient with an asymptomatic inguinal hernia in which a large part of the abdominal content had herniated into the scrotum without strangulation. In such cases, surgery is indicated to relieve the symptoms, cosmetically correct the defect and to prevent future complications. ${ }^{4,5}$

\section{References}

1. Fitzgibbons RJ Jr, Giobbie-Hurder A, Gibbs JO, Dunlop DD, Reda DJ, McCarthy M Jr, et al. Watchful waiting vs repair of inguinal hernia in minimally symptomatic men: A randomized clinical trial. JAMA 2006; 295:285-92. doi: 10.1001/jama. 295.3.285.

2. Quintas ML, Rodrigues CJ, Yoo JH, Rodrigues Junior AJ. Agerelated changes in the elastic fiber system of the interfoveolar ligament. Rev Hosp Clin Fac Med Sao Paulo 2000; 55:83-6. doi: $10.1590 /$ S0041-87812000000300003.

3. Isik A, Gursul C, Peker K, Aydın M, Firat D, Yılmaz I. Metalloproteinases and their inhibitors in patients with inguinal hernia. World J Surg 2017 [Epub ahead of print]. doi: $10.1007 / \mathrm{s} 00268-016-3858-6$.

4. Fitzgibbons RJ Jr, Ramanan B, Arya S, Turner SA, Li X, Gibbs JO, et al. Long-term results of a randomized controlled trial of a nonoperative strategy (watchful waiting) for men with minimally symptomatic inguinal hernias. Ann Surg 2013; 258:508-15. doi: 10.1097/sla.0b013e3182a19725.

5. O'Dwyer PJ, Norrie J, Alani A, Walker A, Duffy F, Horgan P. Observation or operation for patients with an asymptomatic inguinal hernia: A randomized clinical trial. Ann Surg 2006; 244:167-73. doi: 10.1097/01.sla.0000217637.69699.ef. 